\title{
Adjunctive imprint cytology of core needle biopsy specimens improved diagnostic accuracy for breast cancer
}

\author{
Shinichiro Kashiwagi ${ }^{*}$, Naoyoshi Onoda', Yuka Asano ${ }^{1}$, Satoru Noda ${ }^{1}$, Hidemi Kawajiri ${ }^{1}$, Tsutomu Takashima $^{1}$, \\ Masahiko Ohsawa², Seiichi Kitagawa ${ }^{3}$ and Kosei Hirakawa'
}

\begin{abstract}
Objective: Recently, therapies targeting the biological characteristics of individual cancers according to markers indicating underlying molecular biological mechanisms have become available. Core needle biopsy (CNB) is widely used, not only to diagnose, but also to determine therapeutic strategies, in patients with breast cancer. Although the diagnostic accuracy of CNB is acceptably high, false-negative results have occasionally been encountered.

Methods: The results of adjunctive imprint cytology (AIC) coinciding with CNB in 2,820 patients suspected to have breast cancer were retrospectively reviewed. The feasibility and clinical usefulness of AIC-assisted diagnosis were analyzed.

Results: Fourteen-hundred and sixty-four cases were diagnosed as not malignant using CNB alone. Forty-seven of 1464 cases were suspected to be malignant on a cytological review of AIC, and 42 were confirmed to be breast cancer on additional biopsies. The combination of CNB and AIC achieved a sensitivity of 100\% (1398/1398) and a specificity of $99.6 \%$ (1417/1422). Small lesions and large noninvasive- or scirrhous-type carcinomas were the common features of the CNB-negative/AIC-positive cases.

Conclusions: Adjunctive imprint cytodiagnosis is a simple and easy procedure that assists the pathological diagnosis of breast cancer using CNB and therefore serves as a possible novel standard application.
\end{abstract}

Keywords: Adjunctive imprint cytology; Biopsy; Breast cancer; Diagnosis; False negative

\section{Introduction}

Recently, molecular biological mechanisms involved in the growth and metastasis of breast cancer have been intimately elucidated. Therapies targeting the biological characteristics of individual cancers according to markers indicating underlying molecular biological mechanisms have become available. For instance, hormone, chemo and HER2/neu molecular-targeting therapies are widely used based on the expression states of estrogen receptor (ER), progesterone receptor (PR), Ki67 and the HER2/neu expression status in cancer cells (Sorlie et al. 2003; Bauer et al. 2007; Rastogi et al. 2008; Perez et al. 2010; Abd El-Rehim et al. 2005; Mattie et al. 2006).

\footnotetext{
* Correspondence: spqv9ke9@view.ocn.ne.jp

'Department of Surgical Oncology, Osaka City University Graduate School of Medicine, 1-4-3 Asahi-machi, Abeno-ku, Osaka 545-8585, Japan

Full list of author information is available at the end of the article
}

Moreover, the expressions of these molecules are also known to have roles as prognostic indicators (Rakha et al. 2006; Sørlie et al. 2006; Rakha et al. 2007). Hence, molecules used as therapeutic targets, as well as prognostic predictors, can be determined prior to the initiation of tailor-made therapies. In order to obtain such molecular information and determine an accurate pathological diagnosis, acquiring sufficient amounts of tissue samples from individual tumors is required. Although open biopsy and Mammotome $^{\circ}$ (MMT) are the best procedures to acquire large amounts of tissue samples (Brem et al. 2001; Verkooijen 2002; Hoorntje et al. 2003), it is not practical to apply these invasive and expensive procedures to every tumor suspected of being breast cancer. The type of subjects considered for these procedures should therefore be limited. 
For these purposes, CNB (core needle biopsy) is universally performed to diagnose breast cancer. We have been employing $\mathrm{CNB}$ as a routine diagnostic procedure in our institute since 2007. For the experienced hand, performing the CNB procedure is very easy, minimally invasive, safe and inexpensive when compared with open biopsy or MMT (Brem et al. 2001). Previous reports of CNB have shown a sensitivity of as high as $86-90 \%$ and a specificity of 89-96\% (Westenend et al. 2001; Hatada et al. 2000; Ballo \& Sneige 1996). Furthermore, the precise characteristics of cancer cells can be investigated from the tissue samples obtained with CNB (Varga et al. 2005; Taucher et al. 2003; Cahill et al. 2006).

However, at the same time, false-negative results have occasionally been encountered in the diagnosis of breast cancer using CNB (Varga et al. 2005; Taucher et al. 2003). The obtained tissue samples are small, and it is sometimes difficult to demonstrate a suitable cut surface on a slide for pathological investigation. Therefore, most diagnostic errors from CNB result from failures to investigate whole specimens due to improperly obtained samples or inadequately presented histological specimens. To improve the diagnostic accuracy of $\mathrm{CNB}$, adjunctive imprint cytodiagnosis (AIC) has been used in our institute. We experienced a number of cases in which significant benefits were gained using this procedure.

We herein retrospectively reviewed and evaluated the usefulness and availability of AIC-assisted CNB for making accurate diagnoses of breast cancer.

\section{Materials and methods}

\section{Patient background}

The subjects included 2,720 consecutive patients suspected to have breast cancer who underwent $\mathrm{CNB}$ and imprint cytodiagnosis at our department between May 2007 and March 2013. Suspicion of the disease was determined on either physical examination, CT scan, magnetic resonance imaging or US. Every lesion was clearly demonstrated and fully investigated on US before any biopsies were performed. Only patients from whom written informed consent was adequately obtained by explaining the procedures and possible outcomes were included. We performed biopsies in cases of category 4-5 BI-RADS classification (Ball et al. 2002; Orel et al. 1999). Several patients with tumors classified as category 3 were also included according to the recommendations of supervising doctors. One-hundred and seventy two patients were excluded from undergoing CNB and directly sent to undergo vacuum-assisted biopsies such as MMT or the selfcontained vacuum-assisted biopsy system (Vacora ${ }^{\circledR}$ ). These patients were suspected to have ductal carcinoma in situ with predominant US findings of ductal dilatation without clear tumor formation. No complications were observed in association with the procedures. No patient diagnosed with benign disease developed malignant disease during the follow-up period of two to 45 months.

\section{Method of CNB and adjunctive imprint cytology (AIC)}

In each patient, local infiltration anesthesia was administered with $0.5 \%$ epinephrine-containing lidocaine hydrochloride for the skin and puncture pathways and around the lesions. Then, $1.5 \mathrm{~mm}$ of skin was excised for biopsy using an ultrasound-guided $16 \mathrm{G}$ biopsy needle. In principle, two biopsies were sampled from each lesion (Figure 1a). In each case, immediately after the tissue sample was taken out from the needle, the tissue sample and the needle were touched and rolled over on a slide glass and fixed with $95 \%$ ethanol (Figure 1b). A cytological diagnosis was made based on the investigation of Papanicolaou stained specimens by approved cytologists and cytopathologists. The specimens were classified into five categories according to the general rules of clinical and pathological recording of breast cancer (Wang \& Ducatman 1998): "normal or benign", "indeterminate", "suspicious for malignancy" and "malignant". The tissue samples were fixed in $10 \%$ buffered formalin. Several serial HE-stained slides were obtained from formalin-fixed and paraffin-embedded tissue samples for pathological examination by more than two pathologists. For the tissue samples diagnosed as cancerous, immunohistochemical staining against ER, PR, Ki67 and HER2/ neu was conducted in addition to the routine pathological diagnosis.
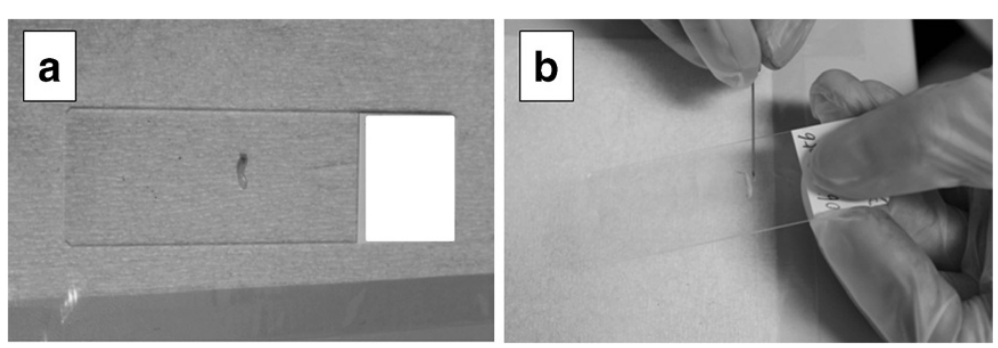

Figure 1 Core needle biopsy and adjunctive imprint cytology methods. In principle, two biopsies were sampled from the each lesion (a). Immediately after the tissue sample itself and the needle were touched they were rolled over on a slide glass and fixed with $95 \%$ ethanol (b). 


\section{Results}

A review of the diagnoses made with $\mathrm{CNB}$ demonstrated that, of all the 2,820 cases, $1,464(51.9 \%)$ were benign and 1356 (48.1\%) were malignant. CNB alone showed a sensitivity of $96.6 \%(1351 / 1398)$, a specificity of $99.6 \%$ (1417/1422) and a false-negative rate of 3.4\% (47/1398). Of the malignant cases, $47(1.7 \%)$ were diagnosed as benign on CNB and suspected of being malignant on AIC. Ultimately, 42 of these 47 patients $(89.4 \%)$ were revealed to have breast cancer (Figure 2).

Table 1 shows the clinico-pathological backgrounds of the 42 cases diagnosed to have breast cancer on AIC. All of the patients were female. Their ages ranged from 30 to 82 (mean: 61.0) years. Thirteen patients were pre-menopausal and twenty-nine patients were post-menopausal. The tumor diameters measured between 0.4 and 8.0 (mean: 1.9) $\mathrm{cm}$. Nine cases involved tumors measuring less than $1 \mathrm{~cm}$ in diameter and 26 (61.9\%) cases involved tumors measuring less than $2 \mathrm{~cm}$ in diameter. In sixteen cases (38.1\%), no tumors were found within the tissue samples obtained with CNB. Ten cases $(23.8 \%)$ were diagnosed as having benign hyperplastic lesions such as adenosis or hyperplasia. And two cases (4.8\%) were necrotic tissue. Atypical cell clusters were found in the CNB specimens of the fourteen remaining cases (33.3\%). Twenty tumors were diagnosed as "suspicious for malignancy" and twenty-two tumors were diagnosed as "malignant" according to the AIC specimens. Diagnoses of breast cancer were obtained with MMT biopsies before surgery, and 33 invasive ductal carcinomas (78.6\%) and nine non-invasive ductal carcinoma in situ (21.4\%) were identified on the final pathological investigations of the surgical specimens. ER and PR were positively identified in 26 (61.9\%) and 21 (50.0\%) cases, respectively. HER2/neu was found to be overexpressed in 12 cases (28.6\%).

In contrast, five tumors (10.6\%) classified as "suspicious for malignancy" on AIC were ultimately revealed to have been diagnosed correctly in the initial pathological review of the CNB specimens. The final pathological diagnosis in five cases was confirmed using MMT biopsies to be benign disease (three cases of fibroadenoma and two cases of intra ductal papilloma). Therefore, of all the 2,820 cases, $1,422(50.4 \%)$ were ultimately diagnosed as benign and 1,398 (49.6\%) were ultimately diagnosed as malignant. Forty-two false-negative cases on pathological review of $\mathrm{CNB}$ and five false-positive cases on cytological review of AIC were found. The combination of $\mathrm{CNB}$ and AIC achieved a sensitivity of $100 \%(1398 / 1398)$ and a specificity of $99.6 \%(1417 / 1422)$ (Table 2$)$.

Figure 3 shows a representative case. A 58-year-old female was found to have a $1.9 \mathrm{~cm}$ tumor on her right breast on US. She underwent CNB on suspicion of having breast cancer. Only a small area of atypical cell clusters was demonstrated in the CNB sample, which was not considered an adequate quantity to diagnose the lesion as breast cancer. On the other hand, AIC classified the tumor as "malignant" based on the demonstration of cancerous cells with papillary clumping. A final diagnosis of invasive ductal carcinoma was made using MMT. This diagnosis was consistent with the pathological features of the surgically resected specimen.

\section{Discussion}

A considerable number of cases have shown discrepancies between clinical images and pathology in the diagnosis of breast lesions. Nevertheless, in cases with strong clinical suspicion of malignancy, most lesions that cannot be proven to be pathologically malignant on biopsy are ultimately revealed to be benign. However, on some occasions, malignant disease can only be identified after repeated investigation, resulting in critical delays in initiating anti-cancer therapy. To avoid these problems, sufficient specimens should be presented for pathological review. Open biopsy or MMT are useful methods for obtaining adequate tissue samples to make accurate

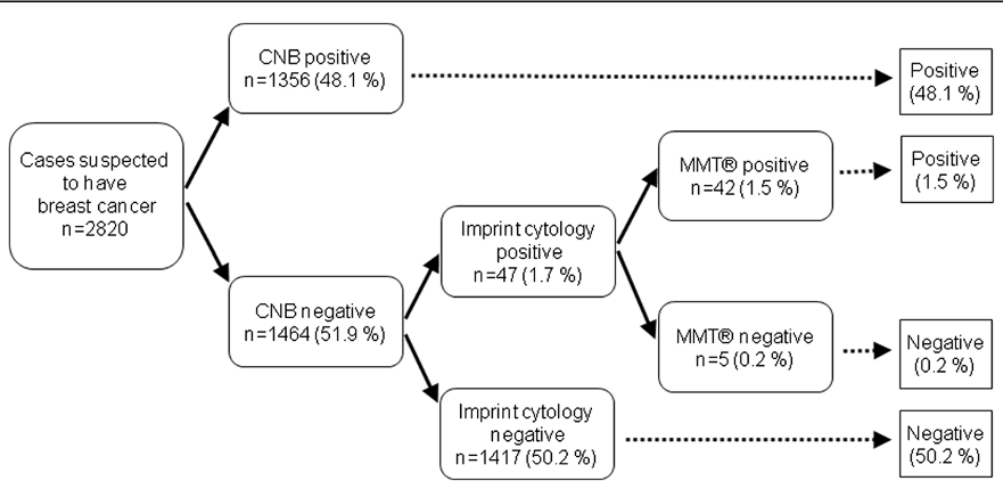

Figure 2 Schema of our diagnostic procedure was shown. A CNB diagnosis demonstrated that, of all the 2,820 cases, 1464 (51.9\%) were benign and 1356 (48.1\%) were malignant. Forty-seven cases (1.7\%) were diagnosed as benign by CNB, but suspected of being malignant by AIC. Finally, 42 of the 47 patients (89.4\%) were revealed to have breast cancer. 
Table 1 Clinico-pathological characteristics of the patients and breast cancers identified by adjunctive imprint cytology of the core-needle biopsied specimens

\begin{tabular}{|c|c|c|c|c|c|}
\hline Age & Menopausal & CNB Dx. & AIC Dx. & Final Dx. & Size $(\mathrm{cm})$ \\
\hline 46 & After & No tumor & SM & $\mathrm{IDC}^{*}$ & 0.4 \\
\hline 66 & Post & No tumor & SM & $\mathrm{DCIS}^{* *}$ & 0.5 \\
\hline 76 & Post & No tumor & SM & IDC & 0.6 \\
\hline 73 & Post & Intraductal papilloma & M & DCIS & 0.7 \\
\hline 67 & Post & Intraductal papilloma & M & IDC & 0.8 \\
\hline 70 & Post & Atypical cell cluster & SM & IDC & 1.0 \\
\hline 56 & Post & Atypical cell cluster & M & IDC & 1.0 \\
\hline 78 & Post & No tumor & M & IDC & 1.0 \\
\hline 52 & Post & Fibrocystic condition & SM & DCIS & 1.0 \\
\hline 46 & After & Chronic mastitis & SM & IDC & 1.2 \\
\hline 41 & After & No tumor & SM & IDC & 1.2 \\
\hline 68 & Post & Apocrine metaplasia & M & DCIS & 1.2 \\
\hline 71 & Post & Necrotic tissue & SM & IDC & 1.2 \\
\hline 67 & Post & Atypical cell cluster & M & IDC & 1.3 \\
\hline 77 & Post & Ductal hyperplasia & M & DCIS & 1.5 \\
\hline 51 & After & No tumor & SM & IDC & 1.5 \\
\hline 33 & After & Adenosis & M & IDC & 1.6 \\
\hline 59 & Post & No tumor & SM & IDC & 1.6 \\
\hline 51 & Post & Atypical cell cluster & SM & IDC & 1.6 \\
\hline 43 & After & No tumor & SM & DCIS & 1.7 \\
\hline 75 & Post & Atypical cell cluster & M & IDC & 1.8 \\
\hline 30 & After & Atypical cell cluster & M & IDC & 1.9 \\
\hline 58 & Post & Atypical cell cluster & M & IDC & 1.9 \\
\hline 75 & Post & No tumor & SM & IDC & 1.9 \\
\hline 74 & Post & Fibrocystic condition & SM & IDC & 2.0 \\
\hline 53 & Post & Atypical cell cluster & SM & IDC & 2.0 \\
\hline 66 & Post & Atypical cell cluster & SM & IDC & 2.1 \\
\hline 64 & Post & Atypical cell cluster & M & IDC & 2.2 \\
\hline 43 & After & Adenosis & M & IDC & 2.4 \\
\hline 42 & After & No tumor & SM & DCIS & 2.4 \\
\hline 78 & Post & Phyllodes suspicious & SM & IDC & 2.4 \\
\hline 82 & Post & No tumor & M & IDC & 2.4 \\
\hline 72 & Post & Atypical cell cluster & M & IDC & 2.6 \\
\hline 62 & Post & No tumor & M & IDC & 2.9 \\
\hline 58 & Post & No tumor & M & IDC & 3.0 \\
\hline 45 & After & Atypical cell cluster & M & IDC & 3.0 \\
\hline 54 & Post & No tumor & SM & IDC & 3.5 \\
\hline 52 & Post & Atypical cell cluster & M & IDC & 3.5 \\
\hline 47 & After & No tumor & SM & IDC & 3.7 \\
\hline 45 & After & Atypical cell cluster & M & DCIS & 4.0 \\
\hline 52 & After & No tumor & M & DCIS & 5.0 \\
\hline 77 & Post & Necrotic tissue & M & IDC & 8.0 \\
\hline
\end{tabular}

CNB core-needle biopsy, Dx. diagnosis, $S M$ suspicious for malignancy, $M$ malignant, $A / C$ adjunctive imprint cytology of the core-needle biopsied, *IDC: invasive ductal carcinoma, ${ }^{* *} D C I S$ : ductal carcinoma in situ. 
Table 2 The results of combination diagnosis with the core-needle biopsy and the $s$ adjunctive imprint cytology

\begin{tabular}{cccc}
\hline CNB/AIC & Benign & Cancer & Total \\
\hline Both negative & 1417 & 0 & 1417 \\
Either positive & 5 & 1398 & 1403 \\
Total & 1422 & 1398 & 2820 \\
\hline
\end{tabular}

CNB core-needle biopsy, $A / C$ adjunctive imprint cytology of the core-needle biopsied specimen.

pathological diagnoses (Brem et al. 2001; Verkooijen 2002; Hoorntje et al. 2003). However, it is not practical to perform these invasive and expensive procedures in every patient, and the simple CNB technique is universally used as a routine method of tissue biopsy in diagnosing the majority of cases of breast cancer (Westenend et al. 2001; Hatada et al. 2000; Ballo \& Sneige 1996). Therefore, maintaining the accuracy of pathological diagnosis with $\mathrm{CNB}$ at the highest level is important.

Previous reports describing the accuracy of pathological diagnosis with CNB have shown sensitivities of as high as $86-90 \%$ and specificities of $89-96 \%$ (Westenend et al. 2001; Hatada et al. 2000; Ballo \& Sneige 1996). In this study, our experience using CNB alone showed a sensitivity of $96.6 \%$, a specificity of $99.6 \%$ and a falsenegative rate of $3.4 \%$, which was in line with the results of previous reports. According to these observations, the diagnostic accuracy of breast cancer with CNB seems to have already reached a peak. Although this level of diagnostic accuracy is acceptable, it is true that occasional false-negative cases still occur.

One of the most compelling explanations for the occurrence of false-negative CNB results is the unintentional loss of the target lesion. Occasionally, only small cancerous tissues are included in CNB specimens, as shown in our case. Even with careful handling, lesions can separate from the specimens during the multitude of steps of tissue processing. However, AIC performed immediately after sampling using a simple imprinting method maintains the cancerous cells within the samples, which supplements the demerits of CNB.

Several tumor features are known to exert negative impacts on making an accurate CNB diagnosis of breast cancer. In many cases of non-invasive ductal carcinoma, the tumors could not be identified clearly on US (Evans 1992) or were found to display predominantly paratumoral features such as ductal dilatation or irregularities (Li et al. 2010). All of these features can be evaluated before performing $\mathrm{CNB}$, and alternate methods should be implemented such as MMT or Vacora ${ }^{\circ}$ (Salem et al. 2009; Wang et al. 2009; Hauth et al. 2008), as stated in the text. On the other hand, several factors might disturb the process of acquiring appropriate tissue specimens for $\mathrm{CNB}$, even when a clear view of the subject is achieved. Sometimes, needles slip on surfaces or cannot penetrate hard lesions (Ljung et al. 2001). The inability to prevent the patient from moving or to secure the puncture devise might result in the failure to obtain tumor-rich material (Ljung et al. 2001). However, even on these occasions, cancer cells can be identified on the surface of the tissue samples or the needle and can be demonstrated on AIC slides.

The stroke of the needles used in this study was $22 \mathrm{~mm}$ long. Therefore, non-tumorous tissues were often included when performing CNB of small lesions. Similar problems appeared when the tumors consisted of mixtures of scattered cancer cells and matrices, such as in cases of non-invasive carcinoma or sclerosing type (scattered
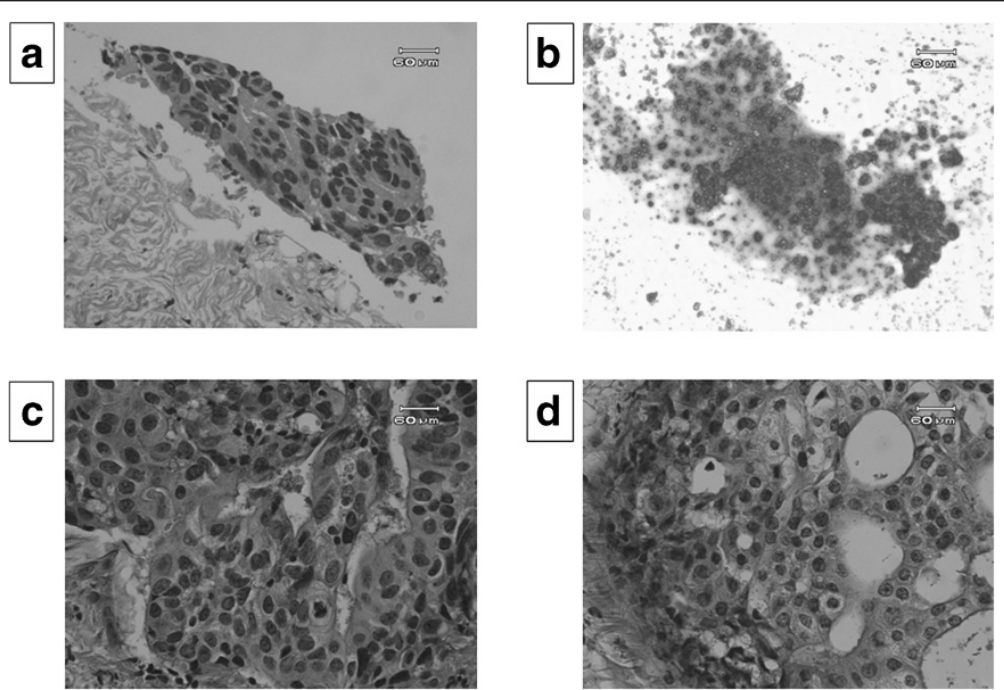

Figure 3 A false negative case was demonstrated. A small area of atypical cell cluster was found in the CNB specimen taken from a 58 yearsold woman with right breast tumor of $1.9 \mathrm{~cm}$ in maximal diameter (a). Adjunctive imprint cytology revealed cancerous cells with papillary clumping (b). Invasive ductal carcinoma was clearly demonstrated in Mammotome ${ }^{\oplus}$ (c) and resected specimens (d). 
cancer cells accompanying predominant fibrotic tissues) carcinoma. On these occasions, the cancer nests occupied only small parts of the specimens, and the targets could not be presented appropriately on the tissue slides for microscopic examination. For these lesions, AIC might therefore have been significantly effective.

The use of cytological examination has critical demerits for investigating the tissue structures of lesions, an important factor used to distinguish breast cancer from benign disease (Ogawa et al. 1998). The experience and individual particularity of the cytologist may increase the false-positive rate of cytological diagnosis, especially for organs, such as the mammary glands, that are highly dependent on hormonal circumstances (Ljung et al. 2001; Pisano et al. 2001; Giard \& Hermans 1992). Therefore, problems remain in the diagnosis of breast cancer using FNA alone. At the same time, cytological diagnosis has superiorities in its ability to oversee whole specimens at a glance, its facility and its non-invasiveness. In several previous reports, the usefulness of AIC for diagnosing cancer involvement in the sentinel lymph nodes has been described (Motomura et al. 2000; Llatjós et al. 2002; Lee et al. 2002). A similar technique was used in the present study in order to supplement the weak points of pathological diagnosis using CNB.

The use of AIC in combination with CNB does not add any burdens to the patient's body and can be performed with small expense. The procedure is not complicated and only requires rolling the tissue samples on the slide glass while confirming whether the obtained tissue specimens are sufficient. Moreover, we demonstrated significant clinical benefits of AIC in improving the pathological diagnosis of breast cancer.

In the present study, we described 42 cases of breast cancer identified using AIC in combination with CNB. No special features in the backgrounds of the patients were observed, indicating the universal applicability of this simple method. More than half of the tumors in the present study measured less than $2 \mathrm{~cm}$ in diameter, and all tumors measuring more than $2 \mathrm{~cm}$ in diameter showed either ductal carcinoma in situ or sclerosing type, histologically. As described earlier, it has been clearly demonstrated that AIC has a significant additional impact for diagnosing lesions with characteristics that indicate possible difficulties in making an accurate diagnosis with CNB alone. In this study, we experienced five false-positive cases with AIC. After confirming the final pathology using tissue obtained by MMT, both cases were revealed to have been diagnosed correctly on CNB. The diseases observed in these five cases (three cases of fibroadenoma and two cases of intra ductal papilloma) tend to be overly diagnosed using cytology (Giard \& Hermans 1992). It may be possible to omit performing MMT with more intimate mutual consultations between surgeons and pathologists.
We herein retrospectively examined the usefulness and applicability of adjunctive imprint cytodiagnosis of core needle biopsied specimens in the diagnosis of breast cancer and found significant benefits for this technique in improving the ability to make an accurate diagnosis. To our knowledge, no previous reports have been published on these issues. Adjunctive imprint cytodiagnosis is a simple and easy procedure that assists the pathological diagnosis of breast cancer with $\mathrm{CNB}$ and therefore serves as a possible novel standard application.

\section{Competing interest}

The authors declare no conflict of interest.

\section{Authors' contributions}

SK participated in the design of the study and drafted the manuscript. NO helped with study data collection and manuscript preparation. YA, SN, HK, TT helped with study data collection and participated in its design. MO helped with data collection and manuscript preparation. SK, KH conceived of the study, and participated in its design and coordination and helped to draft the manuscript. All have read and approved the final manuscript.

\section{Author details}

'Department of Surgical Oncology, Osaka City University Graduate School of Medicine, 1-4-3 Asahi-machi, Abeno-ku, Osaka 545-8585, Japan. ²Department of Diagnostic Pathology, Osaka City University Graduate School of Medicine, 1-4-3 Asahi-machi, Abeno-ku, Osaka 545-8585, Japan. ${ }^{3}$ Department of Physiology, Osaka City University Graduate School of Medicine, 1-4-3 Asahi-machi, Abeno-ku, Osaka 545-8585, Japan.

Received: 30 July 2013 Accepted: 1 August 2013

Published: 6 August 2013

\section{References}

Abd El-Rehim DM, Ball G, Pinder SE, Rakha E, Paish C, Robertson JF, Macmillan D, Blamey RW, Ellis IO (2005) High-throughput protein expression analysis using tissue microarray technology of a large well-characterised series identifies biologically distinct classes of breast cancer confirming recent cDNA expression analyses. Int J Cancer 116(3):340-350

Ball CG, Butchart M, MacFarlane JK (2002) Effect on biopsy technique of the breast imaging reporting and data system (BI-RADS) for nonpalpable mammographic abnormalities. Can J Surg 45(4):259-263

Ballo MS, Sneige N (1996) Can core needle biopsy replace fine-needle aspiration cytology in the diagnosis of palpable breast carcinoma. A comparative study of 124 women. Cancer 78(4):773-777

Bauer KR, Brown M, Cress RD, Parise CA, Caggiano V (2007) Descriptive analysis of estrogen receptor (ER)-negative, progesterone receptor (PR)-negative, and HER2-negative invasive breast cancer, the so-called triple-negative phenotype: a population-based study from the California cancer Registry. Cancer 109(9):1721-1728

Brem RF, Schoonjans JM, Sanow L, Gatewood OM (2001) Reliability of histologic diagnosis of breast cancer with stereotactic vacuum-assisted biopsy. Am Surg 67(4):388-392

Cahill RA, Walsh D, Landers RJ, Watson RG (2006) Preoperative profiling of symptomatic breast cancer by diagnostic core biopsy. Ann Surg Oncol 13(1):45-51

Evans WP (1992) Fine-needle aspiration cytology and core biopsy of nonpalpable breast lesions. Curr Opin Radiol 4(5):130-138

Giard RW, Hermans J (1992) The value of aspiration cytologic examination of the breast. A statistical review of the medical literature. Cancer 69(8):2104-2110

Hatada T, Ishii H, Ichii S, Okada K, Fujiwara Y, Yamamura T (2000) Diagnostic value of ultrasound-guided fine-needle aspiration biopsy, core-needle biopsy, and evaluation of combined use in the diagnosis of breast lesions. J Am Coll Surg 190(3):299-303

Hauth EA, Jaeger HJ, Lubnau J, Maderwald S, Otterbach F, Kimmig R, Forsting M (2008) MR-guided vacuum-assisted breast biopsy with a handheld biopsy system: clinical experience and results in postinterventional MR mammography after $24 \mathrm{~h}$. Eur Radiol 18(1):168-176 
Hoorntje LE, Peeters PH, Mali WP, Borel Rinkes IH (2003) Vacuum-assisted breast biopsy: a critical review. Eur J Cancer 39(12):1676-1683

Lee A, Krishnamurthy S, Sahin A, Symmans WF, Hunt K, Sneige N (2002) Intraoperative touch imprint of sentinel lymph nodes in breast carcinoma patients. Cancer 96(4):225-231

Li JL, Wang ZL, Su L, Liu XJ, Tang J (2010) Breast lesions with ultrasound imaging-histologic discordance at 16-gauge core needle biopsy: can rebiopsy with 10-gauge vacuum-assisted system get definitive diagnosis? Breast 19(6):446-449

Ljung BM, Drejet A, Chiampi N, Jeffrey J, Goodson WH, 3rd, Chew K, Moore DH 2nd, Miller TR (2001) Diagnostic accuracy of fine-needle aspiration biopsy is determined by physician training in sampling technique. Cancer 93(4):263-268

Llatjós M, Castellà E, Fraile M, Rull M, Julián FJ, Fusté F, Rovira C, FernándezLlamazares J (2002) Intraoperative assessment of sentinel lymph nodes in patients with breast carcinoma: accuracy of rapid imprint cytology compared with definitive histologic workup. Cancer 96(3):150-156

Mattie MD, Benz CC, Bowers J, Sensinger K, Wong L, Scott GK, Fedele V Ginzinger D, Getts R (2006) Haqq C (2006) Optimized high-throughput microRNA expression profiling provides novel biomarker assessment of clinical prostate and breast cancer biopsies. Mol Cancer 5:24

Motomura K, Inaji H, Komoike Y, Kasugai T, Nagumo S, Noguchi S, Koyama H (2000) Intraoperative sentinel lymph node examination by imprint cytology and frozen sectioning during breast surgery. Br J Surg 87(5):597-601

Ogawa Y, Kato Y, Nakata B, Yoshikawa K, Kawabata S, Wakasa K, Sakurai M, Sowa M (1998) Diagnostic potential and pitfalls of ultrasound-guided fine-needle aspiration cytology for breast lesions. Surg Today 28(2):167-272

Orel SG, Kay N, Reynolds C, Sullivan DC (1999) BI-RADS categorization as a predictor of malignancy. Radiology 211(3):845-850

Perez EA, Moreno-Aspitia A, Aubrey Thompson E, Andorfer CA (2010) Adjuvant therapy of triple negative breast cancer. Breast Cancer Res Treat 120(2):285-291

Pisano ED, Fajardo LL, Caudry DJ, Sneige N, Frable WJ, Berg WA, Tocino I, Schnitt SJ, Connolly JL, Gatsonis CA, McNeil BJ (2001) Fine-needle aspiration biopsy of nonpalpable breast lesions in a multicenter clinical trial: results from the radiologic diagnostic oncology group V. Radiology 219(3):785-792

Rakha EA, El-Rehim DA, Paish C, Green AR, Lee AH, Robertson JF, Blamey RW, Macmillan D, Ellis IO (2006) Basal phenotype identifies a poor prognostic subgroup of breast cancer of clinical importance. Eur J Cancer 42(18):3149-3156

Rakha EA, El-Sayed ME, Green AR, Lee AH, Robertson JF, Ellis IO (2007) Prognostic markers in triple-negative breast cancer. Cancer 109(1):25-32

Rastogi P, Anderson SJ, Bear HD, Geyer CE, Kahlenberg MS, Robidoux A Margolese RG, Hoehn JL, Vogel VG, Dakhil SR, Tamkus D, King KM, Pajon ER, Wright MJ, Robert J, Paik S, Mamounas EP, Wolmark N (2008) Preoperative chemotherapy: updates of National Surgical Adjuvant Breast and Bowel Project Protocols B-18 and B-27. J Clin Oncol 26(5):778-785

Salem C, Sakr R, Chopier J, Antoine M, Uzan S, Daraï E (2009) Pain and complications of directional vacuum-assisted stereotactic biopsy: comparison of the Mammotome and Vacora techniques. Eur J Radiol 72(2):295-299

Sorlie T, Tibshirani R, Parker J, Hastie T, Marron JS, Nobel A, Deng S, Johnsen H, Pesich R, Geisler S, Demeter J, Perou CM, Lønning PE, Brown PO, BørresenDale AL, Botstein D (2003) Repeated observation of breast tumor subtypes in independent gene expression data sets. Proc Natl Acad Sci U S A 100(14):8418-8423

Sørlie T, Perou CM, Fan C, Geisler S, Aas T, Nobel A, Anker G, Akslen LA, Botstein D, Børresen-Dale AL, Lønning PE (2006) Gene expression profiles do not consistently predict the clinical treatment response in locally advanced breast cancer. Mol Cancer Ther 5(11):2914-2918

Taucher S, Rudas M, Mader RM, Gnant M, Sporn E, Dubsky P, Roka S, Bachleitner T, Fitzal F, Kandioler D, Wenzel C, Steger GG, Mittlböck M, Jakesz R (2003) Influence of neoadjuvant therapy with epirubicin and docetaxel on the expression of HER2/neu in patients with breast cancer. Breast Cancer Res Treat 82(3):207-213

Varga Z, Caduff R, Pestalozzi B (2005) Stability of the HER2 gene after primary chemotherapy in advanced breast cancer. Virchows Arch 446(2):136-141

Verkooijen HM (2002) Diagnostic accuracy of stereotactic large-core needle biopsy for nonpalpable breast disease: results of a multicenter prospective study with 95\% surgical confirmation. Int J Cancer 99(6):853-859
Wang HH, Ducatman BS (1998) Fine needle aspiration of the breast. A probabilistic approach to diagnosis of carcinoma. Acta Cytol 42(2):285-289

Wang ZL, Li JL, Su L, Zhang YF, Tang J (2009) An evaluation of a 10-gauge vacuum-assisted system for ultrasound-guided excision of clinically benign breast lesions. Breast 18(3):192-196

Westenend PJ, Sever AR, Beekman-De Volder HJ, Liem SJ (2001) A comparison of aspiration cytology and core needle biopsy in the evaluation of breast lesions. Cancer 93(2):146-150

doi:10.1186/2193-1801-2-372

Cite this article as: Kashiwagi et al:: Adjunctive imprint cytology of core needle biopsy specimens improved diagnostic accuracy for breast cancer. SpringerPlus 2013 2:372.

\section{Submit your manuscript to a SpringerOpen ${ }^{\circ}$ journal and benefit from:}

- Convenient online submission

- Rigorous peer review

- Immediate publication on acceptance

- Open access: articles freely available online

- High visibility within the field

- Retaining the copyright to your article

Submit your next manuscript at $>$ springeropen.com 